\title{
Illegitimate $\mathrm{V}(\mathrm{D}) \mathrm{J}$ recombination involving non-antigen receptor loci in lymphoid malignancy
}

\author{
Masahiro Onozawa ${ }^{1}$ and Peter D. Aplan ${ }^{1}$ \\ ${ }^{1}$ Genetics Branch, Center for Cancer Research, National Cancer Institute, National Institute of \\ Health, Bethesda, MD
}

\section{Abstract}

$\mathrm{V}(\mathrm{D}) \mathrm{J}$ recombination of antigen-receptor loci $(I G H, I G K, I G L, T C R A, T C R B, T C R G, T C R D)$ is an essential mechanism that confers enormous diversity to the mammalian immune system. However, there are now at least six examples of intra-chromosomal interstitial deletions caused by aberrant $\mathrm{V}(\mathrm{D}) \mathrm{J}$ recombination between non-antigen receptor loci; five of these six are associated with lymphoid malignancy. The $S I L-S C L$ fusion, and deletions of $C D K N 2 A, I K Z F 1$, Notch1, and $B c 111 b$ are all associated with lymphoid malignancy. These interstitial deletions seem to be species specific, as the deletions seen in mice are not seen in humans; the converse is true as well. Nucleotide sequence analysis of these rearrangements reveals the hallmarks of V(D)J recombination, including site-specificity near cryptic heptamer signal sequences, exonucleolytic "nibbling" at the junction site, and non-templated " $N$ " region nucleotide insertion at the junction site. Two of these interstitial deletions (murine Notch1 and Bcl11b deletions) have been detected, at low frequency, in tissues from healthy mice with no evidence of malignancy, similar to the finding of chromosomal translocations in the peripheral blood or tonsils of healthy individuals. The contention that these are mediated via $\mathrm{V}(\mathrm{D}) \mathrm{J}$ recombination is strengthened by in vivo assays using extra-chromosomal substrates, and chromatin immunoprecipitation-sequence (ChIP-Seq) analysis which shows Rag2 binding at the sites of rearrangement. Although the efficiency of these "illegitimate" recombination events is several orders of magnitude less than that at bona fide antigen receptor loci, the consequence of such deletions, namely activation of proto-oncogenes or deletion of tumor suppressor genes, is devastating, and a major cause for lymphoid malignancy.

\section{Keywords}

lymphoid leukemia; V(D)J recombination; SCL; CDKN2A; IKZF1; NOTCH1; BCL11B

\section{INTRODUCTION}

\section{Normal VDJ recombination}

During normal B- and T-lymphocyte differentiation, a somatic recombination event leads to a physical reconfiguration of genomic DNA in lymphocytes. Non-contiguous V (variable), $\mathrm{D}$ (diversity) and $\mathbf{J}$ (joining) gene segments become juxtaposed to one another, and form a single exon which encodes the variable region of an immunoglobulin (Ig) or T-cell receptor (TCR) protein. This process is known as $\mathrm{V}(\mathrm{D}) \mathrm{J}$ recombination, and has been recognized at seven distinct genomic loci in mammals (Oettinger, 1999). These seven loci (TCRA, TCRB, $T C R G, T D R D, I G H, I G L, I G K)$ encode immunoglobulin or T-cell receptor proteins;

Correspondence: Peter D. Aplan, NIH/NCI/CCR/Genetics Branch, 41 Center Drive, Room B900, Bethesda, MD 20892, aplanp@mail.nih.gov. 
together, these loci are referred to as antigen receptor loci. The diversity, or D segment is placed in parentheses, since not all antigen receptor loci contain D segments.

$\mathrm{V}(\mathrm{D}) \mathrm{J}$ recombination is initiated by cleavage at specific recombination signal sequences (RSSs) that flank V, D, and J segments (Fig. 1A); these RSSs consist of highly conserved heptamer (consensus sequence $5^{\prime}$-CACA/TGTG-3') and nonamer (consensus sequence $5^{\prime}$ ACAAAAACC- $3^{\prime}$ ) motifs that are separated by a spacer of 12 or $23 \pm 1$ nucleotides (Fig. 1B). The heptamer sequence is considered to be the essential recognition element, and within the heptamer, the four nucleotides closest to the fusion site (boxed in Fig. 1B) are the most important (Hesse et al., 1989; Gellert, 1992). On the other hands, the nanomer sequence is not always required for $\mathrm{V}(\mathrm{D}) \mathrm{J}$ recombination (Gellert, 1992). DNA-double strand cleavage at the RSS is mediated by a lymphocyte specific endonuclease complex, encoded by recombination activating gene $(R A G) 1$ and 2 . The DNA double-strand break (DSB) induced by RAG-mediated cleavage is repaired by the action of the non-homologous end joining (NHEJ) DNA DSB repair complex, leading to excision of intervening genomic DNA segments between the D and J segments, and reconfigured genomic DNA that has fused the D and $\mathbf{J}$ segments. A second, analagous recombination event takes place between the $\mathrm{V}$ and DJ segments, resulting in an exon that contains VDJ sequences (Akira et al., 1987; Hesse et al., 1989; Akamatsu et al., 1994).

\section{VDJ recombination between TCR or Ig and non-antigen receptor loci}

Although $\mathrm{V}(\mathrm{D}) \mathrm{J}$ recombination is normally limited to antigen receptor loci, illegitimate $\mathrm{V}$ (D)J recombination events between antigen receptor loci (IG or TCR) and non-antigen receptor loci, resulting in reciprocal chromosomal translocations involving the IG or TCR loci, have been recognized in both B and T-lineage leukemias (Kuppers and Dalla-Favera, 2001; Lieber et al., 2006; Marculescu et al., 2006). Studies of recurrent breakpoint sequences have suggested that some of these translocations may be caused by "illegitimate" recombination between a bona fide antigen receptor RSS, and a sequence that resembles an RSS (a "cryptic" RSS or cRSS).

\section{Site-specific $V(D) J$ recombination between non-antigen receptor loci}

In addition to chromosomal translocations between an antigen receptor locus and a protooncogene, there are now numerous reports implicating "illegitimate" $\mathrm{V}(\mathrm{D}) \mathrm{J}$ recombination between two non-antigen receptor loci, usually in association with a lymphoid malignancy. The result of these recombination events is an intra-chromosomal interstitial deletion typically between 10-200 kb. As mentioned above, although V(D)J recombinase-mediated inter-chromosomal translocations between an antigen receptor locus and a non-antigen receptor locus have been described, there are no examples of chromosomal translocations caused by illegitimate $\mathrm{V}$ (D)J recombination involving two non-antigen receptor loci. These illegitimate recombinations include those between $S I L$ and $S C L$, as well as interstitial deletions involving the $C D K N 2 A$, IKZF1, HPRT, Notch1, and Bcl11b genes (Table 1). In this review, we discuss these recurrent deletions, their clinical and biological implications, and the evidence that they are mediated by illegitimate $\mathrm{V}(\mathrm{D}) \mathrm{J}$ recombination.

SIL-SCL (STIL-TAL1)—SCL (also known as TAL-1), which encodes a transcription factor that is required for normal hematopoiesis (Begley, 1994; Orkin, 1995), was originally identified at the site of a $t(1 ; 14)$ chromosomal translocation in a patient with a hematopoietic "stem" cell leukemia (Begley et al., 1989). This translocation juxtaposed the body of the $S C L$ gene with the TCRD enhancer, leading to unscheduled expression of $S C L$ in hematopoietic cells. Subsequent studies demonstrated that $S C L$ translocations involving the $T C R B$ and TCRA loci were also recognized in patients with T-cell acute lymphoblastic leukemia (T-ALL) (Begley and Green, 1999). 
A recurrent, site-specific interstitial deletion of $90 \mathrm{~kb}$ that disrupted the $S C L$ locus was initially identified in several T-ALL cell lines (Aplan et al., 1990; Brown et al., 1990), and confirmed in studies of primary T-ALL patient samples (Brown et al., 1990). This interstitial deletion juxtaposes the $5^{\prime}$ regulatory region and exon 1 of the $S I L$ ( $S C L$ interrupting locus) gene to intron 1 of the $S C L$ gene (Fig. 2A). A fusion mRNA transcript is produced from this mutant allele, with exon 1 of $S I L$ spliced to exon 3 of $S C L$. Since exon 1 of SIL and the first two exons of $S C L$ are all non-coding exons, the fusion mRNA does not encode a fusion protein, but rather encodes a full-length SCL protein, and the net result of this interstitial deletion is to bring SCL under control of SIL regulatory elements, leading to mis-expression of SCL.

Close examination of the nucleotide sequence at and flanking the genomic breakpoints revealed the following features (Fig. 2B). First, there were sequences that were close matches for the consensus heptamer sequence located precisely at the recombination site of both the $S I L$ and $S C L$ loci. Second, there were non-templated nucleotides added at the junction site, reminiscent of "N" region addition. Third, there was a variable number of nucleotides deleted from both the SIL and SCL loci, similar to the exonucleolytic "nibbling" seen at normal antigen receptor coding joins. These features, site-specificity, directed by cryptic heptamer sequences, $\mathrm{N}$ region addition, and exonucleolytic "nibbling" led to the conclusion that the SIL-SCL fusion was mediated by illegitimate V(D)J recombination between two non-antigen receptor loci.

Subsequent studies revealed that this $S I L-S C L$ rearrangement (also know as the $T A L^{d}$ ) was present in approximately $26 \%$ of childhood T-ALL patients and $16 \%$ of adult T-ALL patients, predominantly in younger adults (Delabesse et al., 1997). A retrospective survey indicated that the $S I L-S C L$ fusion does not confer an increased or decreased risk of induction failure or relapse (Aplan et al., 1992). PCR amplification of both genomic DNA and RNA of the $S I L-S C L$ fusion have been used as a minimal residual disease (MRD) marker in patients whose leukemic cells contain this fusion (van Dongen et al., 1999). Mice that express a SIL-SCL transgene under the control of SIL regulatory elements do not show an increased incidence of leukemic transformation, however, mice that express both a SIL$S C L$ transgene and $L M O 1$ develop T-ALL within 6 months, with almost complete penetrance (Aplan et al., 1997). The T-ALL that develop in these mice is preceded by aberrant thymocyte differentiation (Chervinsky et al., 1999; Herblot et al., 2000), and is likely mediated by a functional inactivation of E-proteins such as E2A and HEB (Chervinsky et al., 1999; Herblot et al., 2000).

CDKN2A and CDKN2B-A segment of chromosome 9p21 contains a 40-kb region encoding the $p 16 / C D K N 2 A$ tumor suppressor gene and two other related genes, $p 14 / A R F$ and $p 15 / C D K N 2 B$, all of which encode factors that are important for cell cycle regulation and/or apoptosis (Kohno and Yokota, 1999; Sherr, 2000). Inactivation of this 9p21 gene cluster by several mechanisms, including deletion, methylation, or point mutation is seen frequently in a wide variety of cancers (Foster et al., 1998; Wiencke et al., 1999; Furonaka et al., 2004). In hematologic malignancies, homozygous deletion of the chromosome 9p21 region is the most common event leading to silencing of these genes, and has been proposed to be a crucial event for the development of ALL, since homozygous deletions of this region have been found in 20-50\% of ALL patients (Ohnishi et al., 1995; Drexler, 1998). In many cases, the deletions are very large, sometimes involving the entire chromosome. However, the breakpoint junctions from 15 ALL cell lines with a 9p21 deletion (9 T- and 6 B-lineage) were analyzed and revealed that the majority (11 lines, $73 \%$ ) of the deletions were mediated by illegitimate $\mathrm{V}(\mathrm{D}) \mathrm{J}$ recombination between $C D K N 2 A$ or $C D K N 2 B$ and MTAP, a gene immediately telomeric to these loci, in both the T- and B-lineage cell lines (Kitagawa et al., 2002). Five breakpoint cluster sites in lymphoid leukemia (BCS-LL) and six sporadic sites 
were identified and noted to contain sequences similar to $\mathrm{V}(\mathrm{D}) \mathrm{J}$ recombination signal sequences. These sites contain $5^{\prime}$-CAC or $3^{\prime}$-GTG trinucleotide sequences that flanked both the distal and proximal breakpoints. Nucleotide sequence of the breakpoint junctions revealed evidence of exonucleolytic "nibbling" from the heptamer sequences and insertions of 1-10 bp nucleotides (N-nucleotide) (Fig. 3A).

As a consequence of this deletion, the $p 16 / C D K N 2 A$ and/or $p 15 / C D K N 2 B$ genes, which encode inhibitors of the cell cycle, become inactivated leading to unopposed RB function and cell cycle progression (Kitagawa et al., 2002). In addition, the $C D K N 2 A$ locus encodes $p 14(A R F)$, a protein that inhibits $M d m 2$, indirectly leading to activation of TP53 (Mullighan et al., 2008; Williams and Sherr, 2008). Thus, deletion of this region results in inactivation of two critical tumor suppressor pathways, those involving RB and TP53.

IKZF1-IKZF1 encodes IKAROS, a member of a family of zinc finger transcription factors that also includes HELIOS, AIOLOS, EOS and PEGASUS. IKAROS is the best characterized of these, and has key roles in the earliest specification of the lymphoid lineage (Rebollo and Schmitt, 2003; Yoshida et al., 2006). The expressions of aberrant, dominantnegative IKAROS isoforms in B- and T-lineage ALL has been previously reported by several groups (Sun et al., 1999; Sun et al., 1999; Sun et al., 1999; Nakase et al., 2000; Tonnelle et al., 2003), although alternative splicing has been reported to be the underlying mechanism (Klein et al., 2006). In addition to these alternate splicing events, deletions of all or a portion of the IKZF1 gene has been identified in $60-80 \%$ of $B C R-A B L 1$ positive ALL cases (Mullighan et al., 2008; Martinelli et al., 2009), suggesting that $I K Z F 1$ deletions complement the $B C R-A B L 1$ fusion. In more than half of these cases, the deletions were confined to a subset of internal IKZF1 exons, most commonly exons 3-6, less commonly exons 1-6 (Mullighan et al., 2008). The genomic deletions were mapped to highly specific regions within introns 1,2 and 6. Moreover, heptamer recombination signal sequences were located immediately internal to the deletion breakpoints, there was evidence of exonucleolytic "nibbling" from the heptamer sequence, and a variable number of additional nucleotides were present between the consensus intron 1 or 2 and 6 sequences, suggesting $\mathrm{N}$ region nucleotide addition (Mullighan et al., 2008; Martinelli et al., 2009). Together, these data suggest that the IKZFI $\triangle 3-6$ and $\triangle 1-6$ deletions arise due to aberrant $\mathrm{V}(\mathrm{D}) \mathrm{J}$ recombination (Fig. 3B).

In addition to the frequent co-occurrence of IKZF1 deletions with BCR-ABL1 positive Blineage ALL, IKZF1 deletions were also detected in $28 \%$ of high risk pediatric $B C R-A B L$ negative B-lineage ALL (Mullighan et al., 2009). In this cohort, alteration of IKZF1 was identified as a predictor of poor outcome (Mullighan et al., 2009). As noted above, IKZF1 deletions are common in $B C R-A B L$ positive ALL and also in lymphoid blast crisis CML (66\%), but not reported in chronic-phase CML, suggesting that the IKZF1 deletion is an important progression event in lymphoid blast crisis (Mullighan et al., 2008; Iacobucci et al., 2009; Martinelli et al., 2009). In pediatric B-cell progenitor ALL, IKZF1 deletions correlated significantly with an increased frequency of relapse at 5 and 10 years and with resistance to chemotherapy (Mullighan et al., 2009). However, the prognostic value of $I K Z F 1$ deletions in adult patients with $B C R$ - $A B L$-positive ALL is still lacking (Martinelli et al., 2009).

The IKZF1 deletions result in haploinsufficiency, expression of a dominant-negative IKAROS isoform, or complete loss of IKAROS expression. Within these, the $\triangle 3-6$ isoform of IKAROS (also known as Ik6) has been shown to act as a dominant-negative inhibitor of the transcriptional activity of IKAROS and related family members (Sun et al., 1996; Sun et al., 1999). Mice homozygous for either an IKZF1 null mutation (Wang et al., 1996) or a dominant-negative IKZF1 mutation (Georgopoulos et al., 1994) exhibit profound defects in 
lymphoid development, and mice heterozygous for a dominant-negative IKZF1 mutation develop clonal T-cell expansions and lymphoproliferative diseases, (Winandy et al., 1995; Dumortier et al., 2006). Interestingly, although IKAROS inactivation leads to T-cell ALL in murine models, loss of IKAROS appears to be rare in human T-cell ALL (Kastner and Chan, 2011).

Notch1-Notch1 signaling is essential for T-lineage commitment as well as for survival and proliferation of normal thymocytes, and Notch1 mutations have been identified in both human and mouse TALL samples (Aster et al., 2008). Deletions of the $5^{\prime}$ portion of the Notch1 gene were originally identified in murine T-ALLs arising after irradiation (Tsuji et al., 2003). Nucleotide sequence analysis revealed the presence of cryptic heptamer or heptamer- and nonamer-like elements, separated by 12-bp or 23-bp spacers, in the vicinity of the genomic breakpoints (Tsuji et al., 2004). In addition, exonucleotyic "nibbling" and nontemplated "N-region" nucleotides were identified at the breakpoint junctions, suggesting that these deletions were also mediated by illegitimate V(D)J recombination. Further support for the hypothesis that these specific $5^{\prime}$-Notch 1 deletions were mediated by illegitimate $\mathrm{V}(\mathrm{D}) \mathrm{J}$ recombination, came from the observation that these deletions were significantly less frequent in thymic lymphomas from Scid mice, and were undetectable in $\mathrm{Rag}^{-/-}$ lymphoma. Interestingly, $5^{\prime}$ Notch 1 deletions did occur in irradiated Scid or Rag $2^{-1-}$ mice, but there was no evidence these were $\mathrm{V}(\mathrm{D}) \mathrm{J}$ mediated, since they were not site specific and had no flanking cryptic heptamer sequences (Tsuji et al., 2004; Tsuji et al., 2009). Recently, these $5^{\prime}$ Notch 1 deletion mutations were also identified in murine TALL cell lines derived from genetically engineered mice (Ashworth et al., 2010). V(D)J recombinase-mediated 5' Notch1 deletions (type 1) were observed in 11 of the 14 cell lines and non-V(D)J recombinase-mediated $5^{\prime}$ Notch 1 deletions (type 2) were observed in 3 of the 14 cell lines. Interestingly, these $5^{\prime}$ Notch 1 deletion frequently accompanied PEST domain mutation (8 of the 14 cell lines). Another group independently reported that spontaneous deletion of $5^{\prime}$ Notch 1 sequences were observed in approximately $75 \%$ of T-ALLs that developed in Ikaros knock down mice (Jeannet et al., 2010). Despite the high frequency of $5^{\prime}$ Notch 1 deletions in murine T-ALL, such lesions were not detected in a large panel of human samples (Ashworth et al., 2010).

The NOTCH1 receptor functions as a ligand-activated transcription factor which transduces extracellular signals from the cell surface to the nucleus (Ferrando, 2009; Paganin and Ferrando, 2011). NOTCH receptors are important for cell fate specification during development and participate in numerous vital biological processes. In the hematopoietic system NOTCH1 activation plays a critical role at several stages of T-cell differentiation (Tanigaki and Honjo, 2007). Notch1 mutations occur in many human and murine T-ALL samples, however, the most common mutations differ between the 2 species (Weng et al., 2004; Lin et al., 2006). In human T-ALL, the most frequent NOTCH1 mutations are point substitutions or small in-frame insertions or deletions in the NOTCH1 heterodimerization domain (HD) which normally holds NOTCH receptors in an inactive state in the absence of ligand. Thus, these HD mutations result in ligand-independent activation of NOTCH1. In contrast, the most common Notch1 mutations in murine T-ALL samples are frameshift mutations that result in premature stop codons and deletion of the C-terminal PEST domain (Weng et al., 2004). Deletion of the PEST domain, which is required for proteasomal degradation of the activated NOTCH1 by the FBXW7/SCF complex, leads to persistent activation of downstream targets of the activated NOTCH1 protein (Thompson et al., 2007). PEST mutations are less frequent in human T-ALL samples, and are often in cis with HD mutations in the same allele. PEST mutations only weakly activate Notch1 signaling in reporter assays and are poorly leukemogenic in mice (Chiang et al., 2008), possibly because Notch1 activation remains ligand-dependent in those assays. 
In samples with the $5^{\prime}$ Notch1 deletion mutations, the deletion removes the $5^{\prime}$ Notch1 promoter as well as the initiator ATG codon within exon1, leading to aberrant Notch1 mRNA initiated from a cryptic promoter within Notch1 exon 25 (Fig. 3C). This leads to production of a Notch1 protein which lacks the ligand-binding extracellular domain and results in the production of an active, intracellular Notch independent of ligand binding and $\gamma$-secretase cleavage. The $5^{\prime}$ Notch1 deletion mutations, which render Notch1 activation ligand-independent, are often accompanied by PEST mutations in mice. Therefore $5^{\prime}$ Notch1 deletions in mice is considered to function similar to the HD mutation in human TALL, both mutations leading to ligand independent activation of Notch1. Thus, the combination of HD + PEST mutation or $5^{\prime}$ deletion + PEST mutation are both considered to be synergistic, whereas a $\mathrm{HD}+5^{\prime}$ deletion mutation would be considered redundant in mechanism and have not been described to occur in the same leukemic sample.

Bcl11b-Bcl1 $b$ encodes a zinc-finger transcription factor that plays an important role in normal T-cell development. In murine thymocytes, Bcl11b inactivation leads to developmental arrest at the DN2-3 stage and aberrant self-renewal activity (Wakabayashi et al., 2003; Ikawa et al., 2010; Li et al., 2010). Mouse thymic lymphomas induced by $\gamma$ irradiation exhibited frequent homozygous deletions of the $B c 111 b$ tumor suppressor gene on chromosome 12 (Sakata et al., 2004). DNA sequences flanking the breakpoint junction sites contained a consensus heptamer sequence, CACAGTG, in intron 3 and a cryptic heptamer sequence, CACACAC, in intron 1. Inspection of the breakpoint junctions again revealed exonucleolytic "nibbling" and random "N" region nucleotide insertion (Fig. 3D). As a result of the interstitial deletion, an in-frame transcript fusing exons 1 and 4 is produced, encoding an alternately spliced form of Bcl11b referred to as the gamma isoform (Wakabayashi et al., 2003).

In human T-ALL, $B C L 11 B$ is involved in the recurrent $\mathrm{t}(5 ; 14)(\mathrm{q} 35 ; \mathrm{q} 32)$ translocation with the $T L X 3$ locus, in which $B C L 11 B$ gene regulatory elements drive aberrant overexpression of the TLX3 oncogene (Nagel et al., 2007). In addition, somatic mutations of $B C L 11 B$ have been reported in most of the major molecular subtypes of human T-ALL. Heterozygous deletions involving BCL11B were identified in 6\% (3 of 47) of primary T-ALL specimens; each deletion pattern was unique and no site-specificity was observed (Gutierrez et al., 2011). Heterozygous missense $B C L 11 B$ mutations were observed in $6 \%$ (7 of 117) of primary T-ALL samples; the deletion and missense mutations of $B C L 11 B$ were mutually exclusive. Thus mutations of $B C L 11 B$ are a recurrent abnormality in both human and mouse T-ALL samples. Although the most commonly observed mutations in mice are homozygous deletions leading to production of an alternately spliced $B c 111 b$ isoform, the most common mutations in human T-ALL are heterozygous deletions or missense mutations.

The mechanism(s) by which $B c 111 b$ mutations might lead to malignant transformation remain unclear. $B c 111 b$-null mice die shortly after birth, exhibiting profound apoptosis of thymocytes (Wakabayashi et al., 2003). Mice which are haplo-insufficient for $B c 111 b$ $(B c 111 b+/-)$ did not develop lymphoma, but were more susceptible to thymic lymphoma than $\mathrm{Bcl1} 1 \mathrm{b+} /+$ mice when irradiated or in combination with the p53+/-genotype (Kamimura et al., 2007). Taken together, these preliminary findings suggest, but do not prove, that $B c 111 b$ may function as a haplo-insufficient tumor suppressor gene.

HPRT-HPRT, which encodes hypoxanthine phosphoribosyl transferase, is a constitutively expressed but nonessential gene located at Xq26 in humans. HPRT converts 6-TG to 6-MP, which is a toxic nucleoside analog; thus, loss of HPRT function leads to 6-TG resistance. Investigators have used the loss of HPRT function as a sensitive assay to estimate mutation frequency (Albertini, 2001). The loss of HPRT function can be due to deletions of all or a portion of the gene, frameshift mutations, or single nucleotide substitutions. While 
investigating the mechanism(s) which might lead to genomic deletions of the HPRT gene, investigators identified a deletion which was consistent with illegitimate $\mathrm{V}(\mathrm{D}) \mathrm{J}$ recombination (Fuscoe et al., 1991). These investigators analyzed 18 mutant lymphocyte clones isolated from 13 normal newborns and identified an identical intron 1 breakpoint and 3 clustered intron 3 breakpoints (Fig. 3E) (Fuscoe et al., 1991). Heptamer-like sequences and unique $\mathrm{N}$-nucleotide insertion were identified at the breakpoint site, supporting the notion that these deletions were mediated by illegitimate $\mathrm{V}(\mathrm{D}) \mathrm{J}$ recombination.

Although, this $H P R T$ deletion has not been described in primary ALL patients, and is not thought to be oncogenic, this specific HPRT deletion appears to be inducible by treatment with etoposide in the CEM cell line. Treatment of the human T-cell leukemia cell line CEM with $5 \mathrm{uM}$ etoposide for $4 \mathrm{hr}$ led to the generation of clones that had a site-specific fusion between intron 1 and 3 (Chen et al., 1996; Chen et al., 1998).

\section{Experimental evidence for illegitimate VDJ recombination}

The nucleotide sequence characteristics described for each of these interstitial deletions, including site-specificity, the presence of cryptic heptamers, addition of non-templated "N" region nucleotides, and exonucleolytic "nibbling" strongly implicate that these deletions are mediated by illegitimate $\mathrm{V}(\mathrm{D}) \mathrm{J}$ recombination between non-antigen receptor loci. To obtain direct experimental evidence that these recombination events were consistent with V(D)J recombination events, several laboratories have applied an extra chromosomal V(D)J recombination assay to assess the functionality of various cryptic recombination signal sequences (cRSSs) in cell culture. The cRSSs present at the breakpoint sites flanking the SIL-SCL fusion were shown to be active in vivo using an extra chromosomal V(D)J rearrangement assay (Raghavan et al., 2001), and reinforced by EMSA assays that demonstrated binding of RAG proteins to oligonucleotide encompassing the SIL and SCL cRSSs (Zhang and Swanson, 2008). An extra chromosomal V(D)J recombination assay using the most frequent recombination site associated with the $M T A P / C D K N 2 A$ deletion demonstrated a recombination potential 150-fold less that the consensus RSSs (Kitagawa et al., 2002). Analysis of cRSSs from the LMO2, LMO1, HOX11, SIL and SCL loci revealed $\mathrm{V}$ (D)J recombination at levels from-30-fold to over 20,000-fold less that a consensus RSS (Zhang and Swanson, 2008).

Deep sequencing techniques have recently enabled investigators to determine preferred binding sites for Rag2 throughout the mouse genome. Rag2 ChIP-Seq data demonstrated binding of Rag2 at the $5^{\prime}$ end of the Notch1 locus, near the exon 1 transcription start site, in wild-type thymocytes (Fig. 4A)(Ashworth et al., 2010; Ji et al., 2010). The major Rag2 binding peak overlapped with the ChIP-Seq peak for histone H3K4 trimethylation (H3K4me3), an activation mark that may be recognized by the plant homology domain of Rag2. Similar to the findings with Notch1, analysis of the publicly available Rag2 ChIP-Seq data for the Bcl11b locus (Ji et al., 2010) demonstrated Rag2 binding peaks at the recombination sites; the $5^{\prime}$ peak also co-localizes with a peak for H3K4-me3 (Fig. 4B). Taken together the combination of nucleotide sequence features, in vivo recombination using extrachromosomal substrates, and in vivo localization of Rag2 binding strongly support the hypothesis that illegitimate $\mathrm{V}(\mathrm{D}) \mathrm{J}$ recombination activity is involved in generation of these interstitial deletions.

\section{Difference in illegitimate $\mathrm{V}(\mathrm{D}) \mathrm{J}$ recombination between species}

With the exception of the HPRT interstitial deletions, all of the interstitial deletions discussed above are known or suspected to contribute to leukemic transformation. Intriguingly, these deletions seem to be species-specific, as the $\mathrm{V}(\mathrm{D}) \mathrm{J}$ recombinase-mediated interstitial deletions involving SIL and $S C L, C D K N 2 A / C D K N 2 B$, and $I K Z F 1$ have been 
reported only in human samples, and those involving Notch1 and $B c 111 b$ have been reported only in mouse T-ALL. However, $S C L$ activation, $C D K N 2 A$ deletion, and $I K Z F 1$ deletion have all been shown to be oncogenic in mice, indicating a potential role for leukemic transformation of each of these genes in mice. Conversely, Notch1 and Bcl11b mutations are observed in $60 \%$ and $10 \%$ of human patients with T-ALL, strongly suggesting the oncogenic potential of these genes in humans as well as mice. Although the reason for this species difference is unknown, we suspect that the difference is due to the random placement of cryptic heptamer sequences, as the cryptic heptamers identified in each of these genes (typically present in non-conserved exonic sequences) are not conserved between human and mouse.

Both Notch1 and $B c 111 b$ deletions have been identified in wild-type mouse thymus, at a low

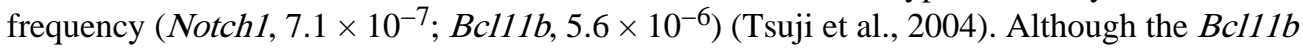
deletion was initially identified in thymic lymphomas induced by $\gamma$-irradiation or $N$-methyl$N$-nitrosourea (MNU) treatment, the frequency of the deletion was not increased by $\gamma$ irradiation (Sakata et al., 2004), suggesting that these deletions were not triggered by DNA damage. Similar to findings with the $5^{\prime}$-Notch1 deletion, $B c 111 b$ deletions were not detected in the thymus of Rag2-knockout mice and were noted at low frequencies in Scid mice, again reinforcing the hypothesis that these deletions are mediated by V(D)J recombinase activity (Sakata et al., 2004; Tsuji et al., 2004).

\section{Summary}

$\mathrm{V}(\mathrm{D}) \mathrm{J}$ recombination is essential for the proper development of the mammalian immune system. However, mistakes in normal V(D)J recombination can lead to deletion of tumor suppressor genes or activation of proto-oncogenes. These illegitimate recombination events have thus far been detected only in lymphoid cells, as would be expected for $\mathrm{V}(\mathrm{D}) \mathrm{J}$ recombination. Although these recombinations can be useful clinical markers for disease, the important challenge now is to devise means by which these aberrant recombination events can be prevented.

\section{Acknowledgments}

We would like to thank members of the Aplan lab, Ilan R. Kirsch, W. Michael Kuehl, Kevin Gardner, and Arito Yamane for helpful advice. We apologize in advance for those authors whose work was not cited due to space limitations. This work was supported by the intramural program of the NCI, NIH. The author (M.O.) is supported by the Japan Society for the Promotion of Science (JSPS), Postdoctoral Fellowships for Research Abroad program.

\section{References}

Akamatsu Y, Tsurushita N, Nagawa F, Matsuoka M, Okazaki K, Imai M, Sakano H. Essential residues in V(D)J recombination signals. J Immunol. 1994; 153:4520-4529. [PubMed: 7963524]

Akira S, Okazaki K, Sakano H. Two pairs of recombination signals are sufficient to cause immunoglobulin V-(D)-J joining. Science. 1987; 238:1134-1138. [PubMed: 3120312]

Albertini RJ. HPRT mutations in humans: biomarkers for mechanistic studies. Mutat Res. 2001; 489:1-16. [PubMed: 11673087]

Aplan PD, Jones CA, Chervinsky DS, Zhao X, Ellsworth M, Wu C, McGuire EA, Gross KW. An scl gene product lacking the transactivation domain induces bony abnormalities and cooperates with LMO1 to generate T-cell malignancies in transgenic mice. EMBO J. 1997; 16:2408-2419. [PubMed: 9171354]

Aplan PD, Lombardi DP, Ginsberg AM, Cossman J, Bertness VL, Kirsch IR. Disruption of the human SCL locus by "illegitimate" V-(D)-J recombinase activity. Science. 1990; 250:1426-1429. [PubMed: 2255914] 
Aplan PD, Lombardi DP, Reaman GH, Sather HN, Hammond GD, Kirsch IR. Involvement of the putative hematopoietic transcription factor SCL in T-cell acute lymphoblastic leukemia. Blood. 1992; 79:1327-1333. [PubMed: 1311214]

Ashworth TD, Pear WS, Chiang MY, Blacklow SC, Mastio J, Xu L, Kelliher M, Kastner P, Chan S, Aster JC. Deletion-based mechanisms of Notch1 activation in T-ALL: key roles for RAG recombinase and a conserved internal translational start site in Notch1. Blood. 2010; 116:54555464. [PubMed: 20852131]

Aster JC, Pear WS, Blacklow SC. Notch signaling in leukemia. Annu Rev Pathol. 2008; 3:587-613. [PubMed: 18039126]

Begley CG. The SCL transcription factor and differential regulation of macrophage differentiation by LIF, OSM and IL-6. Stem Cells. 1994; 12(Suppl 1):143-149. discussion 149-151. [PubMed: 7696958]

Begley CG, Aplan PD, Davey MP, Nakahara K, Tchorz K, Kurtzberg J, Hershfield MS, Haynes BF, Cohen DI, Waldmann TA, et al. Chromosomal translocation in a human leukemic stem-cell line disrupts the T-cell antigen receptor delta-chain diversity region and results in a previously unreported fusion transcript. Proc Natl Acad Sci U S A. 1989; 86:2031-2035. [PubMed: 2467296]

Begley CG, Green AR. The SCL gene: from case report to critical hematopoietic regulator. Blood. 1999; 93:2760-2770. [PubMed: 10216069]

Brown L, Cheng JT, Chen Q, Siciliano MJ, Crist W, Buchanan G, Baer R. Site-specific recombination of the tal-1 gene is a common occurrence in human T cell leukemia. EMBO J. 1990; 9:3343-3351. [PubMed: 2209547]

Chen CL, Fuscoe JC, Liu Q, Relling MV. Etoposide causes illegitimate V(D)J recombination in human lymphoid leukemic cells. Blood. 1996; 88:2210-2218. [PubMed: 8822941]

Chen CL, Woo MH, Neale GA, Goorha RM, Fuscoe JC, Behm FG, Mathew S, Relling MV. A human lymphoid leukemia cell line with a V(D)J recombinase-mediated deletion of hprt. Mutat Res. 1998; 403:113-125. [PubMed: 9726012]

Chervinsky DS, Zhao XF, Lam DH, Ellsworth M, Gross KW, Aplan PD. Disordered T-cell development and T-cell malignancies in SCL LMO1 double-transgenic mice: parallels with E2Adeficient mice. Mol Cell Biol. 1999; 19:5025-5035. [PubMed: 10373552]

Chiang MY, Xu L, Shestova O, Histen G, L'Heureux S, Romany C, Childs ME, Gimotty PA, Aster JC, Pear WS. Leukemia-associated NOTCH1 alleles are weak tumor initiators but accelerate Kras-initiated leukemia. J Clin Invest. 2008; 118:3181-3194. [PubMed: 18677410]

Delabesse E, Bernard M, Landman-Parker J, Davi F, Leboeuf D, Varet B, Valensi F, Macintyre EA. Simultaneous SIL-TAL1 RT-PCR detection of all tal(d) deletions and identification of novel tal(d) variants. Br J Haematol. 1997; 99:901-907. [PubMed: 9432040]

Drexler HG. Review of alterations of the cyclin-dependent kinase inhibitor INK4 family genes p15, p16, p18 and p19 in human leukemia-lymphoma cells. Leukemia. 1998; 12:845-859. [PubMed: 9639410]

Dumortier A, Jeannet R, Kirstetter P, Kleinmann E, Sellars M, dos Santos NR, Thibault C, Barths J, Ghysdael J, Punt JA, Kastner P, Chan S. Notch activation is an early and critical event during TCell leukemogenesis in Ikaros-deficient mice. Mol Cell Biol. 2006; 26:209-220. [PubMed: 16354692]

Ferrando AA. The role of NOTCH1 signaling in T-ALL. Hematology Am Soc Hematol Educ Program. 2009:353-361. [PubMed: 20008221]

Foster SA, Wong DJ, Barrett MT, Galloway DA. Inactivation of p16 in human mammary epithelial cells by CpG island methylation. Mol Cell Biol. 1998; 18:1793-1801. [PubMed: 9528751]

Furonaka O, Takeshima Y, Awaya H, Ishida H, Kohno N, Inai K. Aberrant methylation of p14(ARF), p15(INK4b) and p16(INK4a) genes and location of the primary site in pulmonary squamous cell carcinoma. Pathol Int. 2004; 54:549-555. [PubMed: 15260845]

Fuscoe JC, Zimmerman LJ, Lippert MJ, Nicklas JA, O’Neill JP, Albertini RJ. V(D)J recombinase-like activity mediates hprt gene deletion in human fetal T-lymphocytes. Cancer Res. 1991; 51:60016005. [PubMed: 1933863]

Gellert M. V(D)J recombination gets a break. Trends Genet. 1992; 8:408-412. [PubMed: 1492365] 
Georgopoulos K, Bigby M, Wang JH, Molnar A, Wu P, Winandy S, Sharpe A. The Ikaros gene is required for the development of all lymphoid lineages. Cell. 1994; 79:143-156. [PubMed: 7923373]

Gutierrez A, Kentsis A, Sanda T, Holmfeldt L, Chen SC, Zhang J, Protopopov A, Chin L, Dahlberg SE, Neuberg DS, Silverman LB, Winter SS, Hunger SP, Sallan SE, Zha S, Alt FW, Downing JR, Mullighan CG, Look AT. The BCL11B tumor suppressor is mutated across the major molecular subtypes of T-cell acute lymphoblastic leukemia. Blood. 2011; 118:4169-4173. [PubMed: 21878675]

Herblot S, Steff AM, Hugo P, Aplan PD, Hoang T. SCL and LMO1 alter thymocyte differentiation: inhibition of E2A-HEB function and pre-T alpha chain expression. Nat Immunol. 2000; 1:138144. [PubMed: 11248806]

Hesse JE, Lieber MR, Mizuuchi K, Gellert M. V(D)J recombination: a functional definition of the joining signals. Genes Dev. 1989; 3:1053-1061. [PubMed: 2777075]

Iacobucci I, Storlazzi CT, Cilloni D, Lonetti A, Ottaviani E, Soverini S, Astolfi A, Chiaretti S, Vitale A, Messa F, Impera L, Baldazzi C, D’Addabbo P, Papayannidis C, Lonoce A, Colarossi S, Vignetti M, Piccaluga PP, Paolini S, Russo D, Pane F, Saglio G, Baccarani M, Foa R, Martinelli G. Identification and molecular characterization of recurrent genomic deletions on $7 \mathrm{p} 12$ in the IKZF1 gene in a large cohort of BCR-ABL1-positive acute lymphoblastic leukemia patients: on behalf of Gruppo Italiano Malattie Ematologiche dell'Adulto Acute Leukemia Working Party (GIMEMA AL WP). Blood. 2009; 114:2159-2167. [PubMed: 19589926]

Ikawa T, Hirose S, Masuda K, Kakugawa K, Satoh R, Shibano-Satoh A, Kominami R, Katsura Y, Kawamoto H. An essential developmental checkpoint for production of the T cell lineage. Science. 2010; 329:93-96. [PubMed: 20595615]

Jeannet R, Mastio J, Macias-Garcia A, Oravecz A, Ashworth T, Geimer Le Lay AS, Jost B, Le Gras S, Ghysdael J, Gridley T, Honjo T, Radtke F, Aster JC, Chan S, Kastner P. Oncogenic activation of the Notch1 gene by deletion of its promoter in Ikaros-deficient T-ALL. Blood. 2010; 116:54435454. [PubMed: 20829372]

Ji Y, Resch W, Corbett E, Yamane A, Casellas R, Schatz DG. The in vivo pattern of binding of RAG1 and RAG2 to antigen receptor loci. Cell. 2010; 141:419-431. [PubMed: 20398922]

Kamimura K, Ohi H, Kubota T, Okazuka K, Yoshikai Y, Wakabayashi Y, Aoyagi Y, Mishima Y, Kominami R. Haploinsufficiency of Bcl11b for suppression of lymphomagenesis and thymocyte development. Biochem Biophys Res Commun. 2007; 355:538-542. [PubMed: 17306224]

Kastner P, Chan S. Role of Ikaros in T-cell acute lymphoblastic leukemia. World J Biol Chem. 2011; 2:108-114. [PubMed: 21765975]

Kitagawa Y, Inoue K, Sasaki S, Hayashi Y, Matsuo Y, Lieber MR, Mizoguchi H, Yokota J, Kohno T. Prevalent involvement of illegitimate V(D)J recombination in chromosome 9p21 deletions in lymphoid leukemia. J Biol Chem. 2002; 277:46289-46297. [PubMed: 12228235]

Klein F, Feldhahn N, Herzog S, Sprangers M, Mooster JL, Jumaa H, Muschen M. BCR-ABL1 induces aberrant splicing of IKAROS and lineage infidelity in pre-B lymphoblastic leukemia cells. Oncogene. 2006; 25:1118-1124. [PubMed: 16205638]

Kohno T, Yokota J. How many tumor suppressor genes are involved in human lung carcinogenesis? Carcinogenesis. 1999; 20:1403-1410. [PubMed: 10426784]

Kuppers R, Dalla-Favera R. Mechanisms of chromosomal translocations in B cell lymphomas. Oncogene. 2001; 20:5580-5594. [PubMed: 11607811]

Li L, Leid M, Rothenberg EV. An early T cell lineage commitment checkpoint dependent on the transcription factor Bc111b. Science. 2010; 329:89-93. [PubMed: 20595614]

Lieber MR, Yu K, Raghavan SC. Roles of nonhomologous DNA end joining, V(D)J recombination, and class switch recombination in chromosomal translocations. DNA Repair (Amst). 2006; 5:1234-1245. [PubMed: 16793349]

Lin YW, Nichols RA, Letterio JJ, Aplan PD. Notch1 mutations are important for leukemic transformation in murine models of precursor-T leukemia/lymphoma. Blood. 2006; 107:2540 2543. [PubMed: 16282337] 
Marculescu R, Vanura K, Montpellier B, Roulland S, Le T, Navarro JM, Jager U, McBlane F, Nadel B. Recombinase, chromosomal translocations and lymphoid neoplasia: targeting mistakes and repair failures. DNA Repair (Amst). 2006; 5:1246-1258. [PubMed: 16798110]

Martinelli G, Iacobucci I, Storlazzi CT, Vignetti M, Paoloni F, Cilloni D, Soverini S, Vitale A, Chiaretti S, Cimino G, Papayannidis C, Paolini S, Elia L, Fazi P, Meloni G, Amadori S, Saglio G, Pane F, Baccarani M, Foa R. IKZF1 (Ikaros) deletions in BCR-ABL1-positive acute lymphoblastic leukemia are associated with short disease-free survival and high rate of cumulative incidence of relapse: a GIMEMA AL WP report. J Clin Oncol. 2009; 27:5202-5207. [PubMed: 19770381]

Mullighan CG, Miller CB, Radtke I, Phillips LA, Dalton J, Ma J, White D, Hughes TP, Le Beau MM, Pui CH, Relling MV, Shurtleff SA, Downing JR. BCR-ABL1 lymphoblastic leukaemia is characterized by the deletion of Ikaros. Nature. 2008; 453:110-114. [PubMed: 18408710]

Mullighan CG, Su X, Zhang J, Radtke I, Phillips LA, Miller CB, Ma J, Liu W, Cheng C, Schulman BA, Harvey RC, Chen IM, Clifford RJ, Carroll WL, Reaman G, Bowman WP, Devidas M, Gerhard DS, Yang W, Relling MV, Shurtleff SA, Campana D, Borowitz MJ, Pui CH, Smith M, Hunger SP, Willman CL, Downing JR. Deletion of IKZF1 and prognosis in acute lymphoblastic leukemia. N Engl J Med. 2009; 360:470-480. [PubMed: 19129520]

Mullighan CG, Williams RT, Downing JR, Sherr CJ. Failure of CDKN2A/B (INK4A/B-ARF)mediated tumor suppression and resistance to targeted therapy in acute lymphoblastic leukemia induced by BCR-ABL. Genes Dev. 2008; 22:1411-1415. [PubMed: 18519632]

Nagel S, Scherr M, Kel A, Hornischer K, Crawford GE, Kaufmann M, Meyer C, Drexler HG, MacLeod RA. Activation of TLX3 and NKX2-5 in $\mathrm{t}(5 ; 14)(\mathrm{q} 35 ; \mathrm{q} 32)$ T-cell acute lymphoblastic leukemia by remote $3^{\prime}$-BCL11B enhancers and coregulation by PU.1 and HMGA1. Cancer Res. 2007; 67:1461-1471. [PubMed: 17308084]

Nakase K, Ishimaru F, Avitahl N, Dansako H, Matsuo K, Fujii K, Sezaki N, Nakayama H, Yano T, Fukuda S, Imajoh K, Takeuchi M, Miyata A, Hara M, Yasukawa M, Takahashi I, Taguchi H, Matsue K, Nakao S, Niho Y, Takenaka K, Shinagawa K, Ikeda K, Niiya K, Harada M. Dominant negative isoform of the Ikaros gene in patients with adult B-cell acute lymphoblastic leukemia. Cancer Res. 2000; 60:4062-4065. [PubMed: 10945610]

Oettinger MA. V(D)J recombination: on the cutting edge. Curr Opin Cell Biol. 1999; 11:325-329. [PubMed: 10395566]

Ohnishi H, Kawamura M, Ida K, Sheng XM, Hanada R, Nobori T, Yamamori S, Hayashi Y. Homozygous deletions of p16/MTS1 gene are frequent but mutations are infrequent in childhood T-cell acute lymphoblastic leukemia. Blood. 1995; 86:1269-1275. [PubMed: 7632931]

Orkin SH. Hematopoiesis: how does it happen? Curr Opin Cell Biol. 1995; 7:870-877. [PubMed: 8608018]

Paganin M, Ferrando A. Molecular pathogenesis and targeted therapies for NOTCH1-induced T-cell acute lymphoblastic leukemia. Blood Rev. 2011; 25:83-90. [PubMed: 20965628]

Raghavan SC, Kirsch IR, Lieber MR. Analysis of the V(D)J recombination efficiency at lymphoid chromosomal translocation breakpoints. J Biol Chem. 2001; 276:29126-29133. [PubMed: 11390401]

Rebollo A, Schmitt C. Ikaros, Aiolos and Helios: transcription regulators and lymphoid malignancies. Immunol Cell Biol. 2003; 81:171-175. [PubMed: 12752680]

Sakata J, Inoue J, Ohi H, Kosugi-Okano H, Mishima Y, Hatakeyama K, Niwa O, Kominami R. Involvement of $\mathrm{V}(\mathrm{D}) \mathrm{J}$ recombinase in the generation of intragenic deletions in the Rit $1 / \mathrm{Bcl} 11 \mathrm{~b}$ tumor suppressor gene in gamma-ray-induced thymic lymphomas and in normal thymus of the mouse. Carcinogenesis. 2004; 25:1069-1075. [PubMed: 14754877]

Sherr CJ. The Pezcoller lecture: cancer cell cycles revisited. Cancer Res. 2000; 60:3689-3695. [PubMed: 10919634]

Sun L, Crotty ML, Sensel M, Sather H, Navara C, Nachman J, Steinherz PG, Gaynon PS, Seibel N, Mao C, Vassilev A, Reaman GH, Uckun FM. Expression of dominant-negative Ikaros isoforms in T-cell acute lymphoblastic leukemia. Clin Cancer Res. 1999; 5:2112-2120. [PubMed: 10473095]

Sun L, Goodman PA, Wood CM, Crotty ML, Sensel M, Sather H, Navara C, Nachman J, Steinherz PG, Gaynon PS, Seibel N, Vassilev A, Juran BD, Reaman GH, Uckun FM. Expression of 
aberrantly spliced oncogenic ikaros isoforms in childhood acute lymphoblastic leukemia. J Clin Oncol. 1999; 17:3753-3766. [PubMed: 10577847]

Sun L, Heerema N, Crotty L, Wu X, Navara C, Vassilev A, Sensel M, Reaman GH, Uckun FM. Expression of dominant-negative and mutant isoforms of the antileukemic transcription factor Ikaros in infant acute lymphoblastic leukemia. Proc Natl Acad Sci U S A. 1999; 96:680-685. [PubMed: 9892693]

Sun L, Liu A, Georgopoulos K. Zinc finger-mediated protein interactions modulate Ikaros activity, a molecular control of lymphocyte development. EMBO J. 1996; 15:5358-5369. [PubMed: 8895580]

Tanigaki K, Honjo T. Regulation of lymphocyte development by Notch signaling. Nat Immunol. 2007; 8:451-456. [PubMed: 17440450]

Thompson BJ, Buonamici S, Sulis ML, Palomero T, Vilimas T, Basso G, Ferrando A, Aifantis I. The SCFFBW7 ubiquitin ligase complex as a tumor suppressor in T cell leukemia. J Exp Med. 2007; 204:1825-1835. [PubMed: 17646408]

Tonnelle C, Imbert MC, Sainty D, Granjeaud S, N'Guyen C, Chabannon C. Overexpression of dominant-negative Ikaros 6 protein is restricted to a subset of B common adult acute lymphoblastic leukemias that express high levels of the CD34 antigen. Hematol J. 2003; 4:104109. [PubMed: 12750728]

Tsuji H, Ishii-Ohba H, Katsube T, Ukai H, Aizawa S, Doi M, Hioki K, Ogiu T. Involvement of illegitimate $\mathrm{V}(\mathrm{D}) \mathrm{J}$ recombination or microhomology-mediated nonhomologous end-joining in the formation of intragenic deletions of the Notch1 gene in mouse thymic lymphomas. Cancer Res. 2004; 64:8882-8890. [PubMed: 15604248]

Tsuji H, Ishii-Ohba H, Noda Y, Kubo E, Furuse T, Tatsumi K. Rag-dependent and Rag-independent mechanisms of Notch1 rearrangement in thymic lymphomas of Atm(-/-) and scid mice. Mutat Res. 2009; 660:22-32. [PubMed: 19000702]

Tsuji H, Ishii-Ohba H, Ukai H, Katsube T, Ogiu T. Radiation-induced deletions in the $5^{\prime}$ end region of Notch1 lead to the formation of truncated proteins and are involved in the development of mouse thymic lymphomas. Carcinogenesis. 2003; 24:1257-1268. [PubMed: 12807718]

van Dongen JJ, Macintyre EA, Gabert JA, Delabesse E, Rossi V, Saglio G, Gottardi E, Rambaldi A, Dotti G, Griesinger F, Parreira A, Gameiro P, Diaz MG, Malec M, Langerak AW, San Miguel JF, Biondi A. Standardized RT-PCR analysis of fusion gene transcripts from chromosome aberrations in acute leukemia for detection of minimal residual disease. Report of the BIOMED-1 Concerted Action: investigation of minimal residual disease in acute leukemia. Leukemia. 1999; 13:19011928. [PubMed: 10602411]

Wakabayashi Y, Watanabe H, Inoue J, Takeda N, Sakata J, Mishima Y, Hitomi J, Yamamoto T, Utsuyama M, Niwa O, Aizawa S, Kominami R. Bcl11b is required for differentiation and survival of alphabeta T lymphocytes. Nat Immunol. 2003; 4:533-539. [PubMed: 12717433]

Wang JH, Nichogiannopoulou A, Wu L, Sun L, Sharpe AH, Bigby M, Georgopoulos K. Selective defects in the development of the fetal and adult lymphoid system in mice with an Ikaros null mutation. Immunity. 1996; 5:537-549. [PubMed: 8986714]

Weng AP, Ferrando AA, Lee W, Morris JPt, Silverman LB, Sanchez-Irizarry C, Blacklow SC, Look AT, Aster JC. Activating mutations of NOTCH1 in human T cell acute lymphoblastic leukemia. Science. 2004; 306:269-271. [PubMed: 15472075]

Wiencke JK, Zheng S, Lafuente A, Lafuente MJ, Grudzen C, Wrensch MR, Miike R, Ballesta A, Trias M. Aberrant methylation of p16INK4a in anatomic and gender-specific subtypes of sporadic colorectal cancer. Cancer Epidemiol Biomarkers Prev. 1999; 8:501-506. [PubMed: 10385139]

Williams RT, Sherr CJ. The INK4-ARF (CDKN2A/B) locus in hematopoiesis and BCR-ABL-induced leukemias. Cold Spring Harb Symp Quant Biol. 2008; 73:461-467. [PubMed: 19028987]

Winandy S, Wu P, Georgopoulos K. A dominant mutation in the Ikaros gene leads to rapid development of leukemia and lymphoma. Cell. 1995; 83:289-299. [PubMed: 7585946]

Yoshida T, Ng SY, Zuniga-Pflucker JC, Georgopoulos K. Early hematopoietic lineage restrictions directed by Ikaros. Nat Immunol. 2006; 7:382-391. [PubMed: 16518393] 
Zhang M, Swanson PC. V(D)J recombinase binding and cleavage of cryptic recombination signal sequences identified from lymphoid malignancies. J Biol Chem. 2008; 283:6717-6727. [PubMed: $18187418]$ 
A)

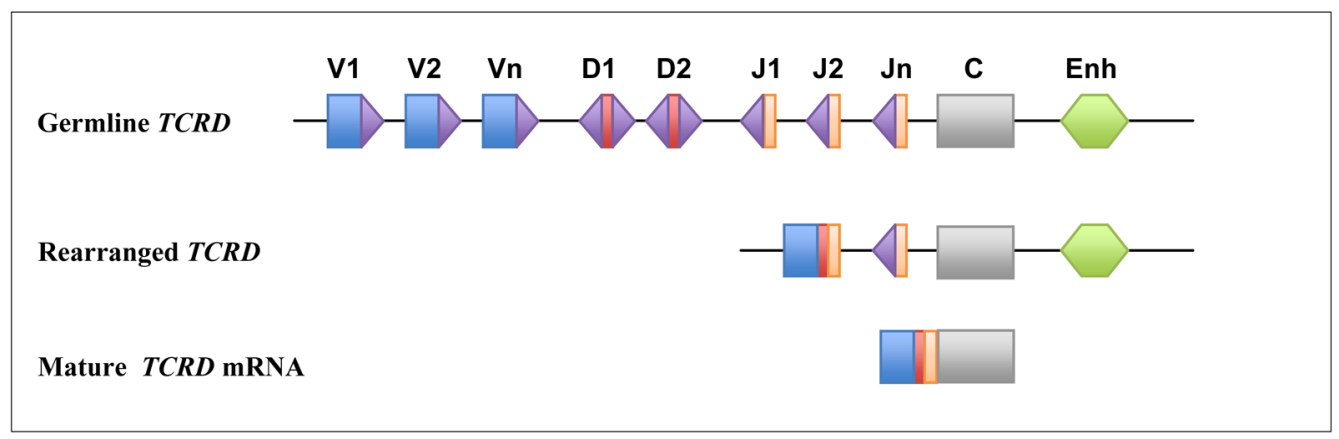

B)

\section{5' -CACAGTG(12 or 23 bp)ACAAAAACC \# GGTTTTTGT(12 or 23 bp)CACTGTG- 3'}

Figure 1. V(D)J recombination at antigen receptor loci

A) Normal V(D)J recombination, with one of many V segments (blue) fusing to a D segment (red) and a J segment (orange). Discreet V, D, and J segments are flanked by heptamer/nonamer sequences (purple triangles). Splicing of the recombined VDJ segment to the $\mathrm{C}$ segment occurs at the RNA level, as depicted. Transcription is regulated by an enhancer region (green). B) Consensus recombination signal sequences. The RSSs normally consists of a highly conserved heptamer motif (consensus sequence $5^{\prime}$-CACA/TGTG-3 ${ }^{\prime}$ ) and a conserved nonamer sequence (consensus sequence $5^{\prime}$-ACAAAAACC- $3^{\prime}$ ) separated by a poorly conserved spacer sequence of 12 or $23 \pm 1 \mathrm{bp}$. The boxed nucleotides closest to the coding sequence are thought to be the most critical for signal specification (see text). 
A)

Germline SIL, SCL (Human Chr 1p33)

Cen

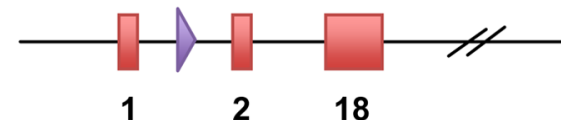

1

18
SIL-SCL interstitial deletion

SIL-SCL fusion mRNA

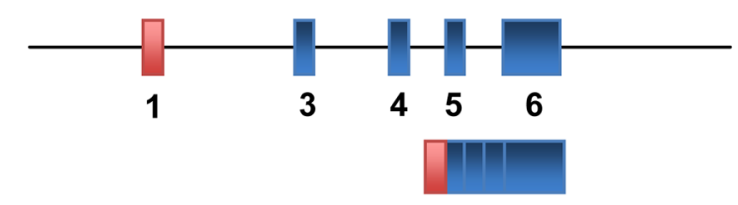

B)

\begin{tabular}{|c|c|}
\hline SIL & 5'-АTTTCTGGCTCA САСTCTG FTACGTAG-3' \\
\hline HSB-2 breakpoint & $\begin{array}{c}\text { 5'-ATTTCTGGCTCA - tct - GTTGGTTTTCATTTC-3' } \\
\|\|\|\|\|\|\end{array}$ \\
\hline CEM breakpoint & $\begin{array}{c}5^{\prime}-\text { ATTTCTGGC } \\
\|\|\|\|\end{array}$ \\
\hline $\begin{array}{l}\text { RPMI8402 breakpoint } \\
\text { SCL }\end{array}$ & 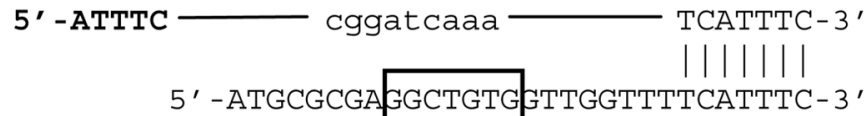 \\
\hline
\end{tabular}

Figure 2. SIL-SCL fusion produced by illegitimate $\mathrm{V}(\mathrm{D}) \mathrm{J}$ recombination

A) Intra-chromosomal deletion between $S I L$ (red exons; only exons 1,2, and 18 are shown for clarity) and $S C L$ (blue exons). Cryptic heptamers within the $S I L$ and $S C L$ loci are depicted by purple triangles. The reconfigured genomic DNA produces a $S I L-S C L$ fusion mRNA, controlled by SIL regulatory elements. B) Nucleotide sequence of germline SIL, germline $S C L$, and the breakpoints from T-ALL cell lines. SIL and $S C L$ germline sequences are in capital letters; SIL sequences are in bold type. Identical nucleotide sequences are indicated by vertical lines. Non-templated nucleotides at the SIL-SCL breakpoints are indicated in lowercase type. Heptamer sequences are boxed. 
A)

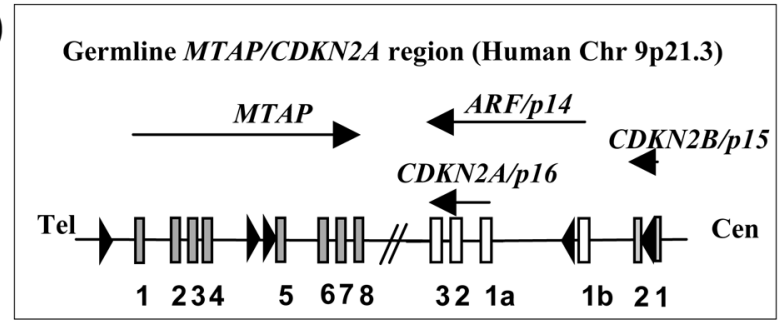

B)

Germline IKZF1 (Human Chr 7p12.2)

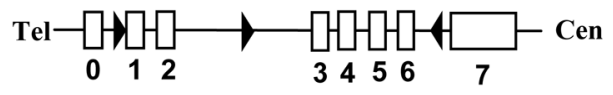

IKZF1 interstitial deletion ( $\triangle 3-6)$

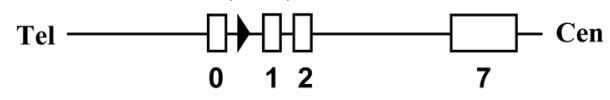

43-6 IKZF1 mRNA

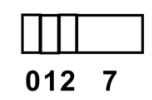

$\triangle$ 3-6 IKZF1 protein

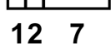

C)

Germline Notch1 (Mouse Chr 2qA3)

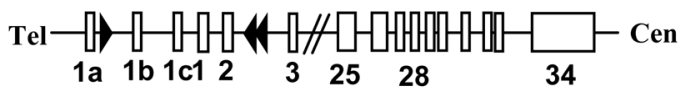

Notchl interstitial deletion

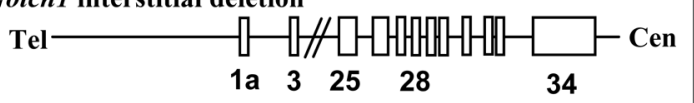

Deleted Notch1 mRNA

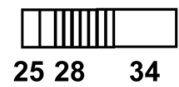

Deleted Notch1 protein

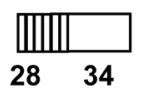
residues encoded by exons 2 and 3 .
D)

Germline Bcl11b (Mouse Chr 12qF1)

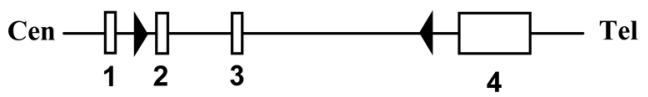

$B c l 11 b$ interstitial deletion

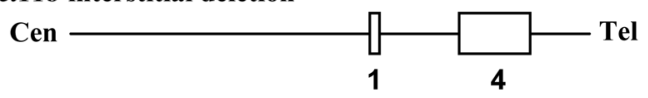

Deleted Bcll1b mRNA

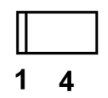

E)

Germline HPRT1 (Human Chr Xq26)

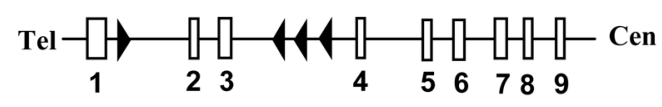

HPRT1 interstitial deletion

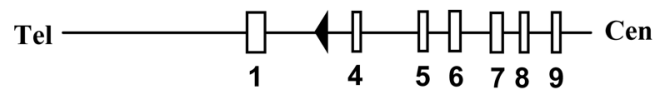

Deleted HPRTI mRNA

Figure 3. V(D)J recombination-mediated interstitial deletion of the indicated gene

A) Human $C D K N 2 A / p 16$ region. Exons of $M T A P, C D K N 2 A, C D K N 2 B$, and $A R F$ are shown, cryptic heptamers are shown as triangle. Centromeric (cen) and telomeric (tel) orientation are indicated. Deletions lead to a loss of $C D K N 2 A$ and $A R F$; some deletions also lead to a loss of CDKN2B. B) Human $I K Z F 1$. Interstitial deletion leads to production of the $\Delta 3-6$ isoform, and the $\Delta 1-6$ deletion does not produce a detectable protein. C) Murine Notch1. The interstitial deletion leads to production of an alternative transcript that begins within exon 25 and initiates translation at a conserved methionine residue, M1727, within the Notch1 transmembrane domain. D) Murine $B c 111 b$. The interstitial deletion leads to an in-frame transcript, producing an alternate isoform of Bcl11b. E) Human HPRT1. The interstitial deletion leads to production of a non-functional protein lacking amino acid 
A)

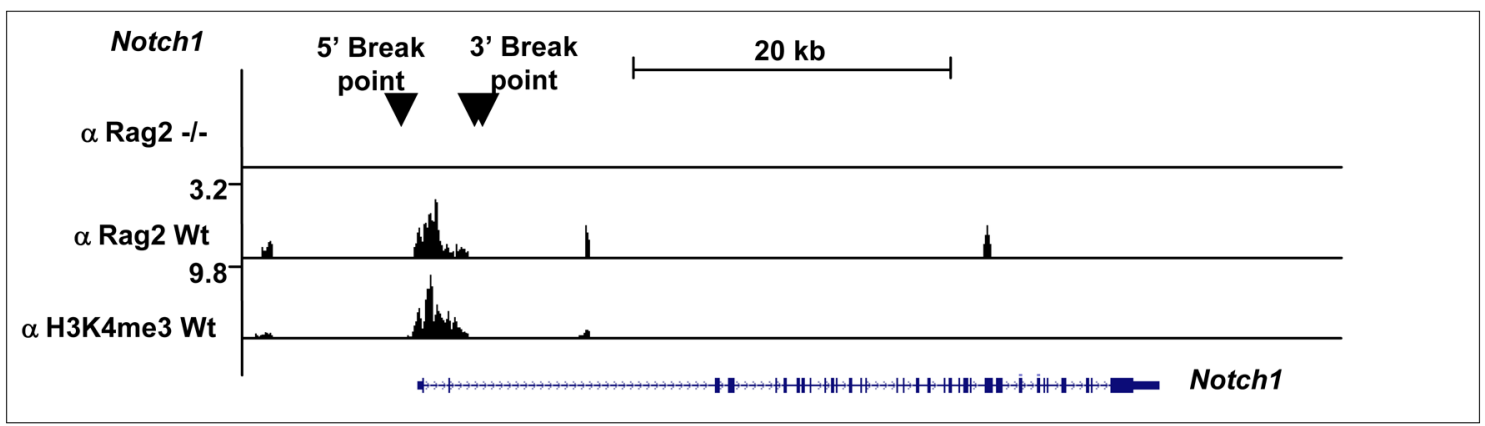

B)

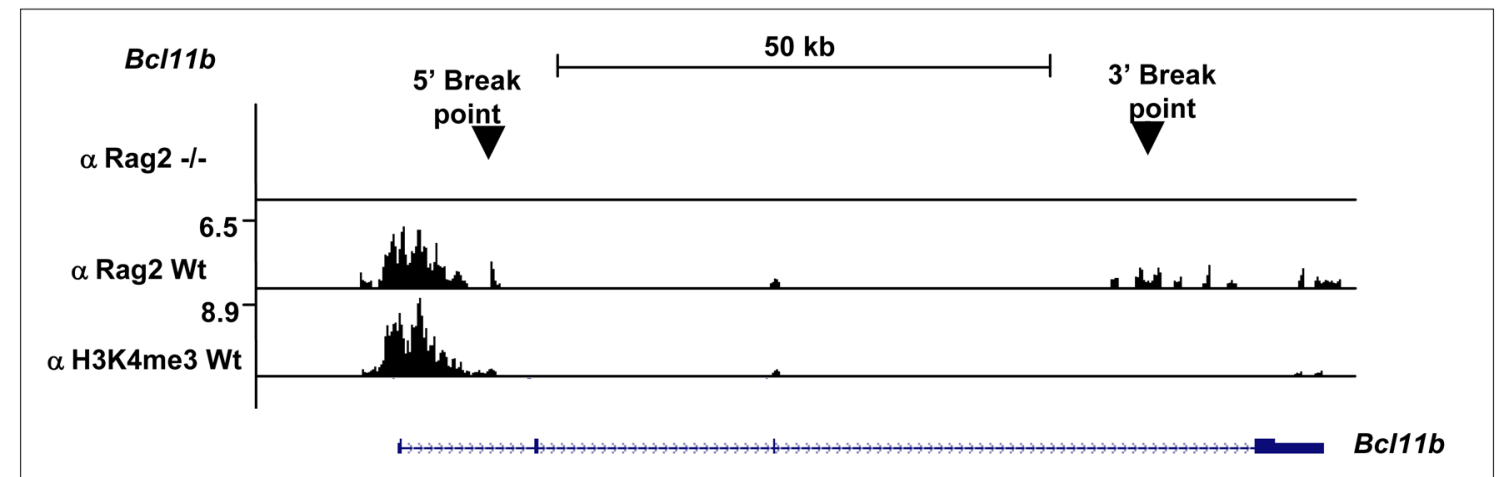

Figure 4. ChIP-Seq demonstrates Rag2 binding nearby Notch1 and Bcl11b breakpoints A) Binding of Rag2 near the transcriptional start site in exon 1 on Notch1 was absent I thymocytes from Rag2-deficient mice ( $\operatorname{Rag} 2-/-)$, but readily detectable in wild-type thymocytes. Transcription start sites co-localize with H3K4me3 binding. Known clustered deletion sites are indicated by arrows. Notch1 genomic structure is as shown. B) Binding of Rag2 near the $5^{\prime}$ and $3^{\prime}$ breakpoint sites of $B c 111 b$ was readily detectable in wild-type thymocytes; $3^{\prime}$ deletion site shows a lesser, more diffuse signal. Known clustered deletion sites are indicated by arrows. Bcl11 b genomic structure is as shown. (Data from Ji et al., 2010; GEO accession: GSE21207.) 


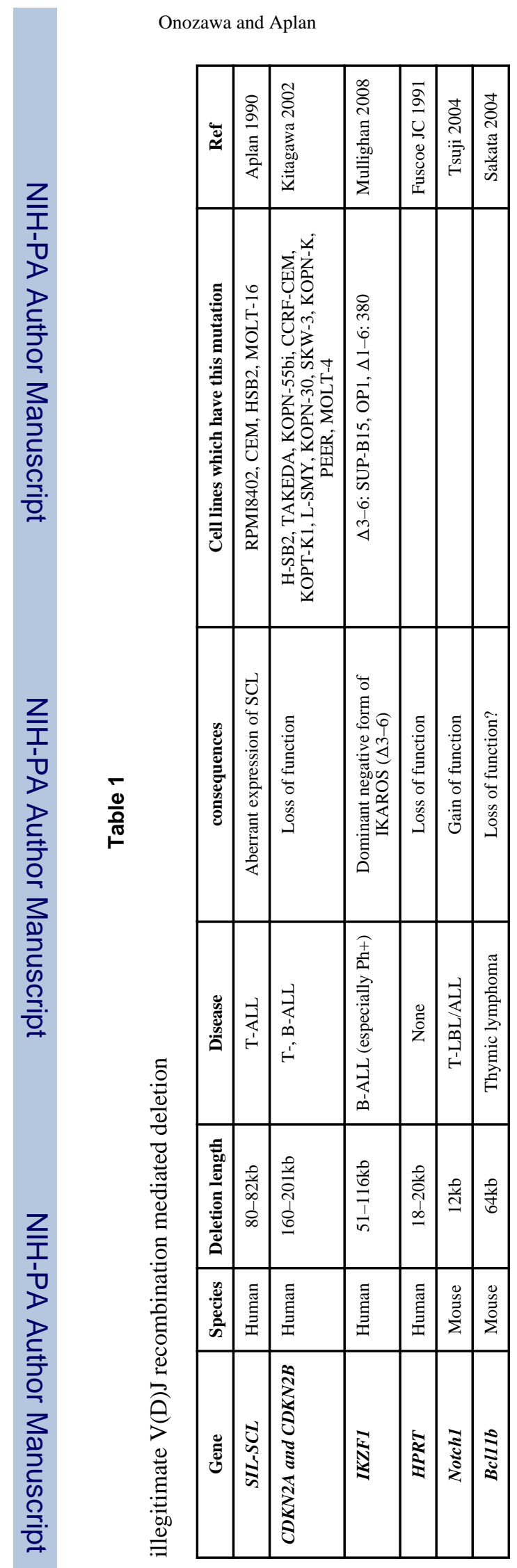

Genes Chromosomes Cancer. Author manuscript; available in PMC 2013 June 01. 